\title{
Comparison of the Efficacy of Three Different Bone Regeneration Materials: An Animal Study
}

\author{
R. Tamil Anbu ${ }^{1} \quad$ V. Suresh ${ }^{1} \quad$ Revathy Gounder ${ }^{1}$ \\ ${ }^{1}$ Department of Prosthodontics, Saveetha Institute of Medical \\ and Technical Sciences, Saveetha Dental College and Hospital, \\ Saveetha University, Chennai, Tamil Nadu, India
}

\section{Abinaya Kannan ${ }^{1}$}

\begin{abstract}
Address for correspondence Revathy Gounder, MDS. Department of Prosthodontics, Saveetha Institute of Medical and Technical Sciences, Saveetha Dental College and Hospital, Affiliated to Saveetha University, Chennai, Tamil Nadu, India (e-mail: revathygounder@yahoo.com).
\end{abstract}

\begin{abstract}
Keywords

- biomaterials

- bone grafts

- bone regeneration

- bone substitutes

- polylactic acid

- three-dimensional

printed polylactic acid

Objective The proposed study aimed to evaluate and compare the bone regeneration between commercially available hydroxyapatite- $\beta$-tricalcium phosphate (Ossifi; Equinox, the Netherlands), powdered polylactic acid (powdered PLA; Sigma-Aldrich, United States), and three-dimensionally printed PLA (3D-printed PLA; Cubex, SC, United States) using 3D printer (Cube X trio) in an animal model.

Materials and Methods Eighteen New Zealand rabbits were divided into three groups with six animals each. Platelet-rich fibrin (PRF) was collected from the venous blood and preserved. Bone defect $(4 \mathrm{~mm} \times 2 \mathrm{~mm}$ ) without disturbing the bone marrow was created and filled with bone graft material (group 1-Ossifi, group 2-powdered PLA, and group 3-3D-printed PLA), over which PRF membranes were placed. The graft material and the barrier were stabilized using resorbable sutures, and all the animals were maintained for 4,8 , and 12 weeks, after which they were euthanized, and bone samples were retrieved. Retrieved bone samples were subjected to radiological and histological analysis.

Results The radiographic and histological changes of 3D-printed PLA in comparison with other two materials (Ossifi and powdered PLA) seemed to have a significant difference. Conclusion 3D-printed PLA scaffolds showed positive signs of bone regeneration around the material in continuity defects. PLA material can be a promising alternative bone regenerative material.
\end{abstract}

\section{Introduction}

A bone graft is defined as an implanted material that promotes bone healing alone or in combination with other materials. ${ }^{1,2}$ The ideal bone graft or bone graft substitutes should provide three essential elements as follows: (1) osteoconductive matrix, (2) osteoinductive properties, and (3) osteogenic cells. ${ }^{3,4}$ The selection of an ideal bone graft relies on several factors such as tissue viability; defect size; graft size, shape, and volume; biomechanical characteristics; graft handling; cost; ethical issues; biological characteristics; and associated complications. ${ }^{5,6}$ Autogenous bone grafts are seldom the most popular material for grafting procedures because of its osteoconductivity and histocompatibility. Alternatives to autogenous materials such as allograft, alloplast, and xenograft are used in grafting, but these carry their own disadvantage at the harvesting site in terms of biocompatibility, required scaffolding nature, and difficulty in obtaining a required anatomic geometry. ${ }^{7-9}$ Biomaterials such as polylactic acid (PLA) and its copolymers with glycolic acid and other hydroxyl acids are of prime importance for orthopedic applications. ${ }^{7}$ They act as a good medium where cellular proliferation, differentiation, collagen formation, and subsequent bone formation are achieved. ${ }^{10,11}$ Although both PLA and PLA polyglycolic acid (PLGA) have been used as bioresorbable suture materials, the literature search indicates lack of using PLA as a scaffold material or as a 
suitable alternative for bone defect reconstruction. ${ }^{12}$ Hence, the proposed study is to evaluate and compare the bone regeneration between the three different bone substitute materials in an animal model.

\section{Materials and Methods}

An animal ethical experiment was approved by the members of Institutional Animal Ethical Committee at Saveetha Medical College and Hospital. The experimental animals included were a breed of New Zealand rabbits weighing equal to or more than $1.5 \mathrm{~kg}$ and more than 1 year of age. The total sample size was 18 . This was calculated based on a study by Nishimoto et al (power set at $80 \%$ ). ${ }^{13}$

The study design had three groups, with six animals in each group. The groups were classified based on the graft material used as group 1-Ossifi graft [Equinox, - Fig. 1], group 2-powdered PLA [Sigma-Aldrich, - Fig. 2], and group 3-three-dimensional (3D) printed PLA ( - Fig. 3) using 3D Printer CubeX trio ( - Fig. 4 ).

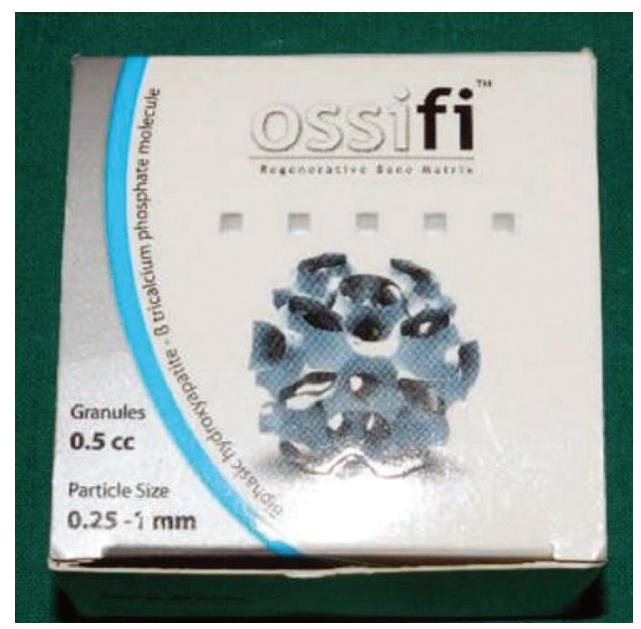

Fig. 1 Ossifie bone graft (Equinox).

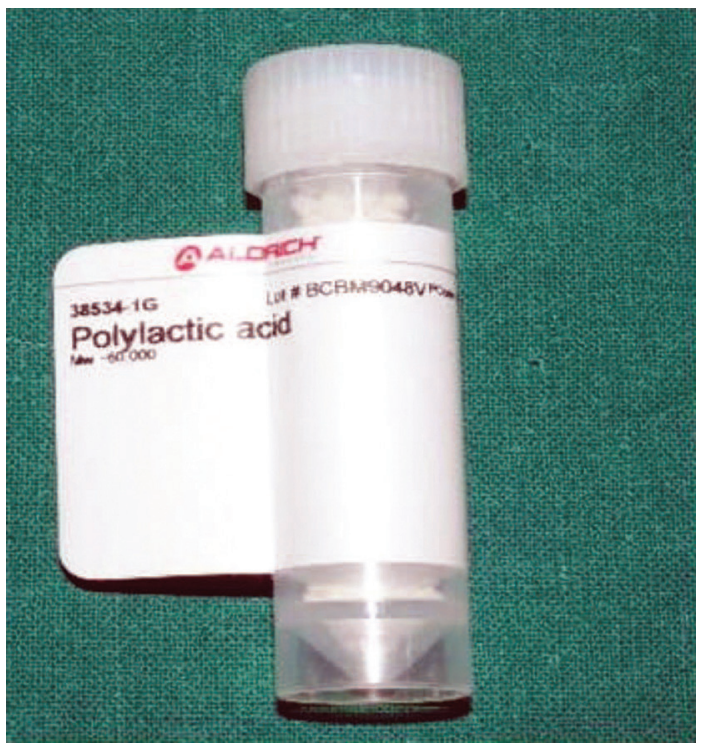

Fig. 2 Powdered form of polylactic acid (Sigma-Aldrich).

\section{Three-Dimensional Printing}

In the Windows operating system using Cubify invent software, a 2D sketch was activated, the virtual scaffolds were designed in cuboidal shape, and exported as a .stl file. The .stl file was built in Cubex; a nondyed PLA material was selected, the file was then exported, and printed in 3D. These cuboidal 3D-printed PLA were pouched and sterilized using steam sterilization.

\section{Surgical Procedure}

Animals were anesthetized using ketamine $22-24 \mathrm{mg} / \mathrm{kg}$ body weight intramuscularly followed by using a Univeter anesthesia unit under isoflurane with an air flow. Platelet-rich fibrin (PRF) was obtained from venous blood and preserved. The medial aspect of femur was exposed through a skin incision approximately $3.5-4.5 \mathrm{~cm}$ running craniolaterally on the surface of the right femur ( - Fig. 5). A surgical drill was used to create a bone defect of size measuring $4 \mathrm{~mm}$ in length, $2 \mathrm{~mm}$ in depth/width without disturbing the bone marrow and the defect was filled with the bone graft material. In group 1-Ossifi grafts (-Fig. 6), Group 2-Powdered PLA (-Fig. 7),

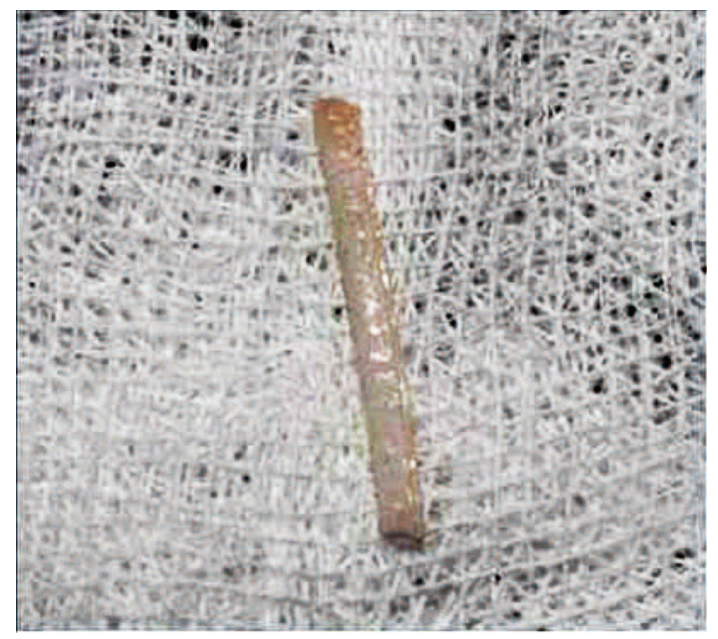

Fig. 3 3D printed polylactic acid (Cubex).

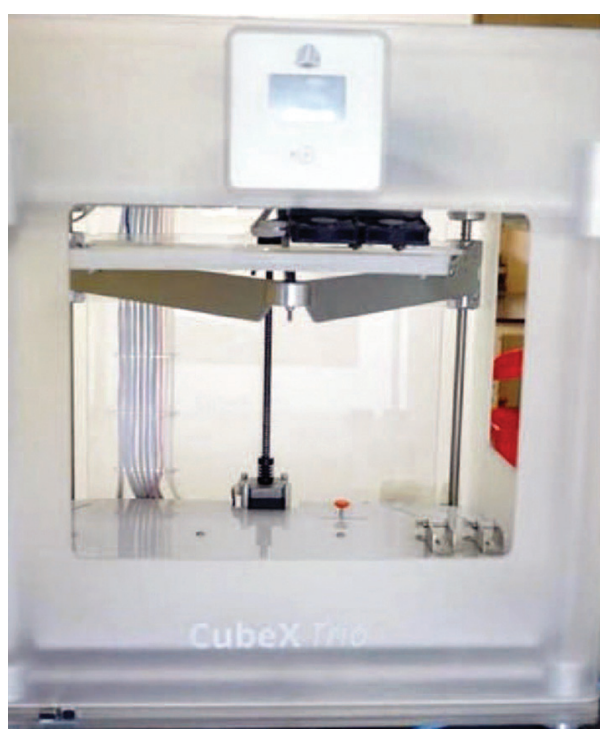

Fig. 4 3D printer. 
and in Group 3-3D-printed PLA ( - Fig. 8) were filled and, over

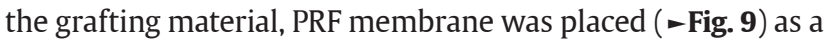
barrier to prevent any soft-tissue ingress into the surgical site.

At 4,8 , and 12 weeks' duration, two animals from each group were euthanized for the retrieval of the femur bone (-Fig. 10) for radiological and histological assessment.

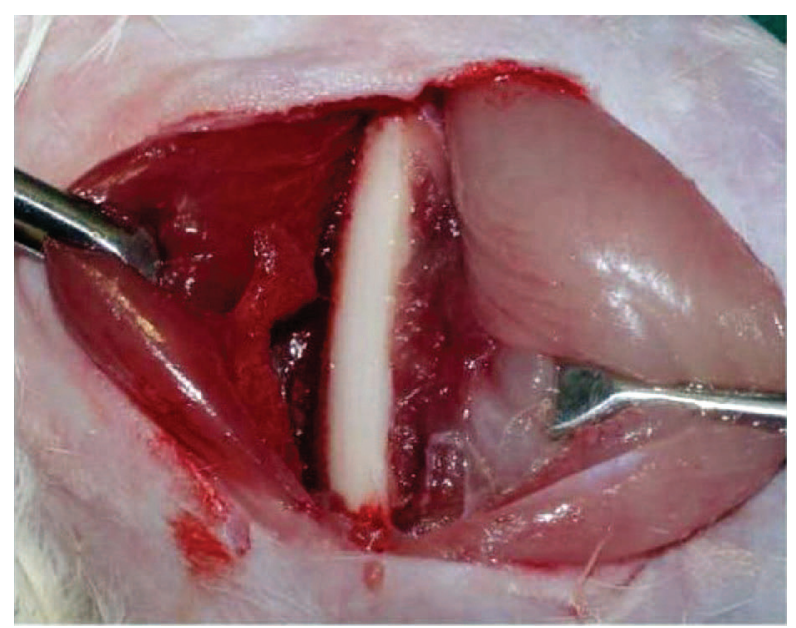

Fig. 5 Exposed femur bone.

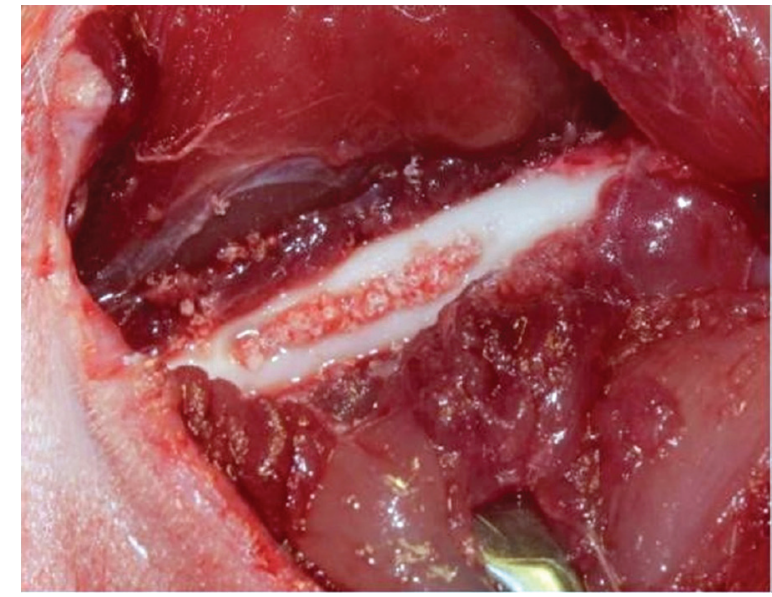

Fig. 6 Defect filled with Ossifie graft.

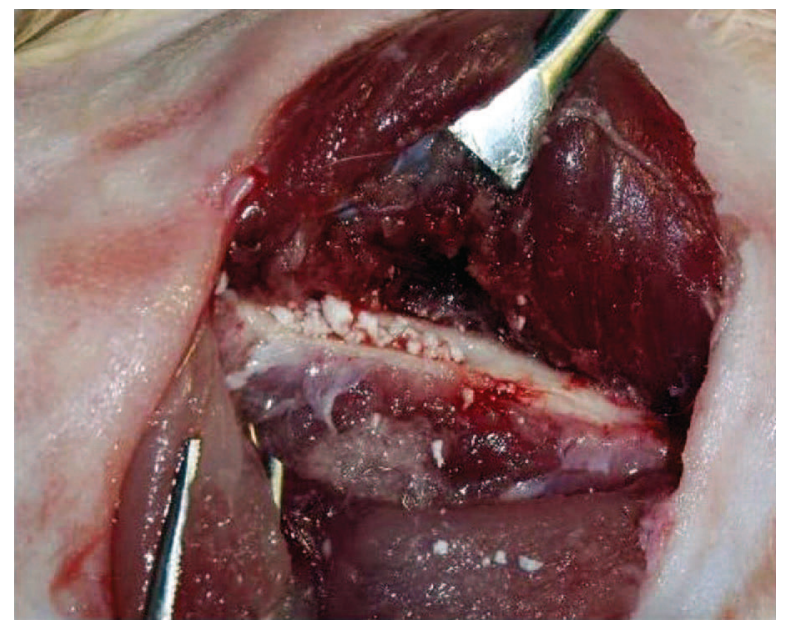

Fig. 7 Defect filled with powdered PLA graft.

\section{Radiological Assessment for Bone Growth}

Computed tomography (CT) scan was done to obtain the radiological data; CT scan was adjusted for sectioning of images at $0.5 \mathrm{~mm}$ slices. The density of bone in the surgical site and the control site was measured using Hounsfield unit ( - Fig. 11a and b).

\section{Histological Assessment}

Following the radiological assessment, the specimens were immersed in a solution of $10 \%$ formaldehyde (Formalin) for $24 \mathrm{~h}$. The tissue samples were cleared off the soft-tissue debris. The specimens were mounted using clear acrylic,

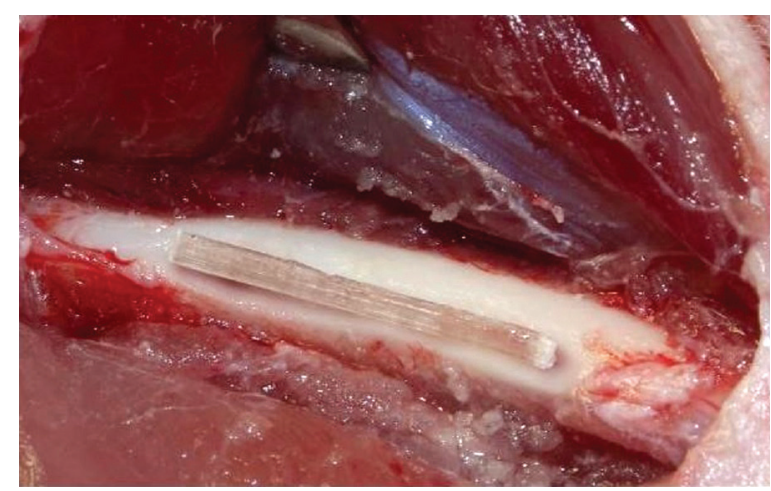

Fig. 8 Defect filled with 3D printed PLA graft.

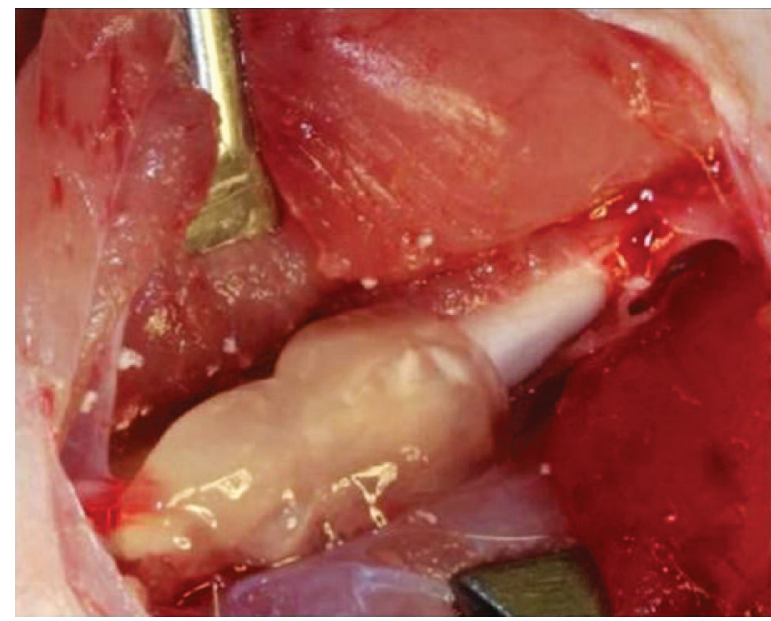

Fig. 9 Platelet rich Fibrin (PRF) membrane placed over the graft.

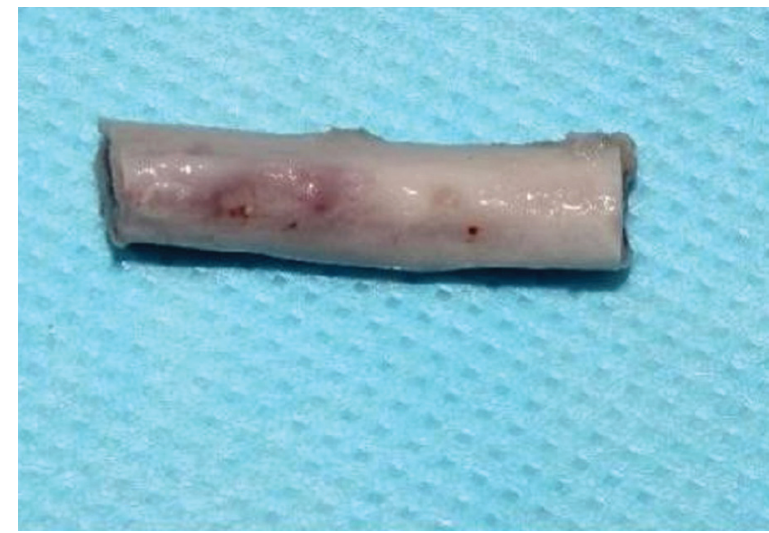

Fig. 10 Retrieved bone sample. 


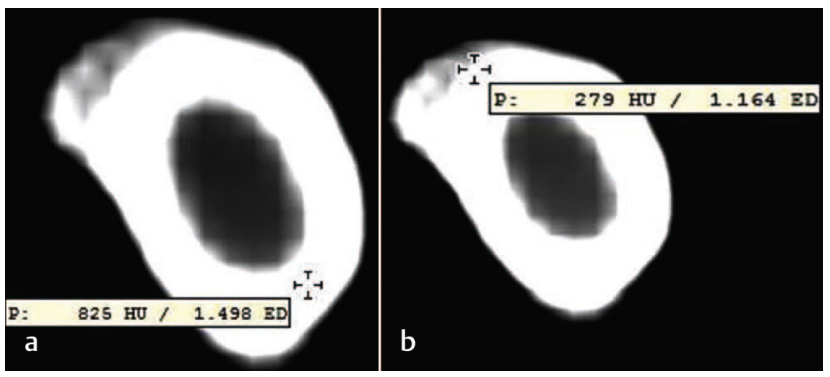

Fig. 11 Cross-sectional CT scan used to measure the bone density at (a) nonsurgical site (b) surgical site.

polymethyl methacrylate orienting the desired region of bone ( - Fig. 12) to be sectioned with hard tissue saw microtome (Leica SP 1600, Leica Biosystems). The thickness of the bone sections was adjusted to be $400 \mu \mathrm{m}$ and was examined under light microscope (Lawrence and Mayo binocular microscope) with $4 \times$ and $10 \times$ magnifications. The parameters that were examined in the slides were the presence or absence of the defect, new bone formed, and the presence or absence of scaffold material ( - Fig. 13).

\section{Results}

In this study, the mean radiodensity at the surgical site as compared to that at the nonsurgical site were observed as follows: In Group 1 (Ossifi), mean radiodensity at sites closer to bone marrow at 4 and 8 weeks was observed to be $341.00 \pm 0.000 \mathrm{HU}$ and $455.50 \pm 20.5 \mathrm{HU}$, respectively. In sites away from the bone marrow, radiodensity values of $233.50 \pm 40.3 \mathrm{HU}$ and $286 \pm 14.84 \mathrm{HU}$ were observed at 4 and 8 weeks, respectively. Powdered PLA showed similar values during the 8 - and 12 -week periods ( $312 \pm 115.9 \mathrm{HU}$ and $343.5 \pm 91.2 \mathrm{HU}$, respectively). The radio-opacity values showed a gradual increase from 4,8 , and 12 weeks at the defect site for 3D-printed PLA (Graph 1). When comparing a surgical site closer to the bone marrow and away from the

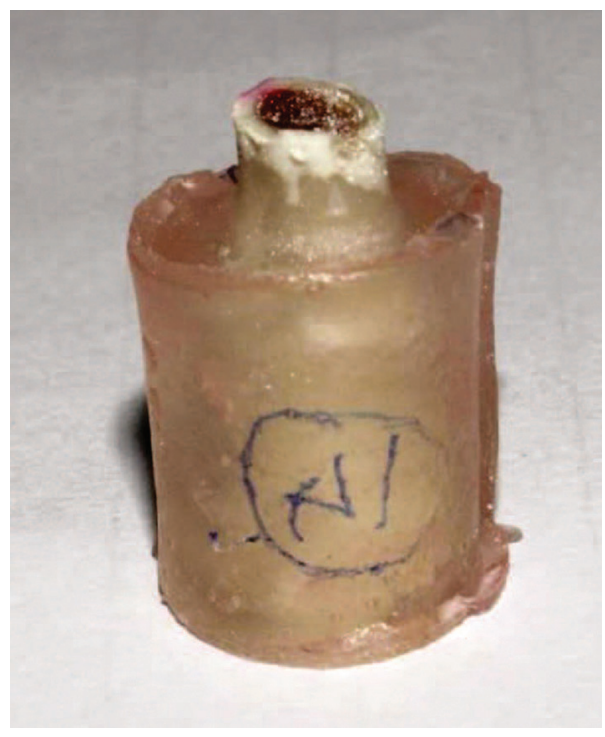

Fig. 12 Mounted bone sample.

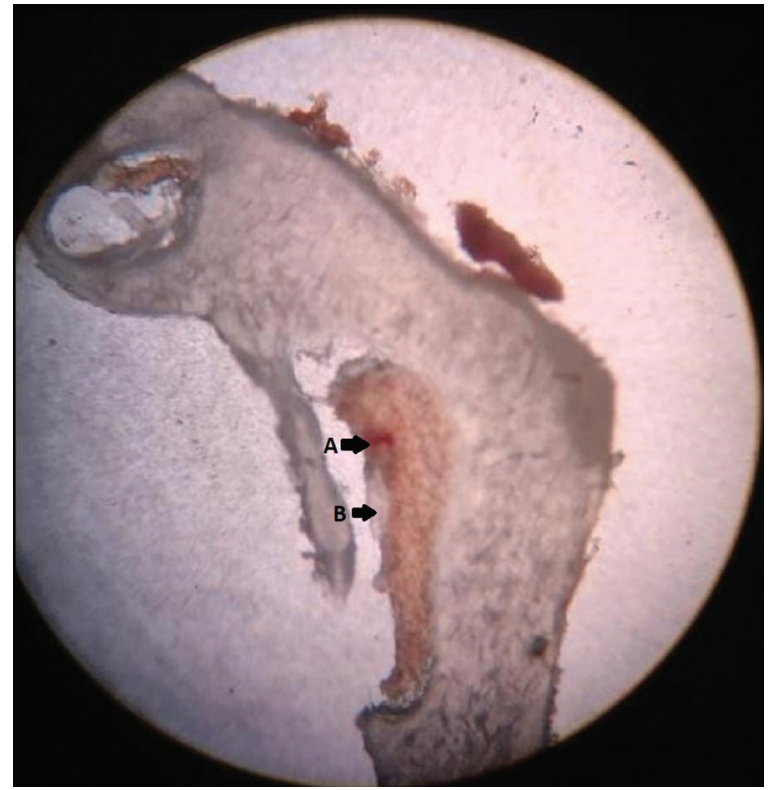

Fig. 13 Specimen examined under light microscope.

bone marrow, Ossifi showed a significant level $(p<0.05)$ of bone formation at 4 and 8 weeks; PLA and 3D-printed PLA revealed a nonsignificant $(p>0.5)$ amount of radiodensity changes between the site closer and away from the bone marrow at 4,8 , and 12 weeks ( - Table $\mathbf{1}$ ).

- Table 2 shows the variation in radiodensity of the bone materials. A significant amount $(p<0.5)$ of dissimilarity of radiodensity was between Ossifi and powdered PLA. Powdered PLA and 3D-printed PLA too had a statistically significant $(p<0.5)$ amount of difference in radiodensity (HU).

In nonparametric analysis ( $\mathbf{- T a b l e ~} \mathbf{3}$ ), there was no significant difference in radiodensity observed between the materials (groups 1,2, and 3) at different time intervals $(4,8$, and 12 weeks) in both the surgical site closer to the bone marrow and the site away from the bone marrow $(p<0.5)$.

Histologically, the presence or absence of bone defect, bone formation, and scaffold degradation was evaluated. The blinded scoring sheets of histological findings were subjected to Kappa statistics. There was a $72 \%$ of acceptance between the observers in terms of bone defect closure, and it was statistically significant $(p<0.05)$. The groups 1 and 3 ,

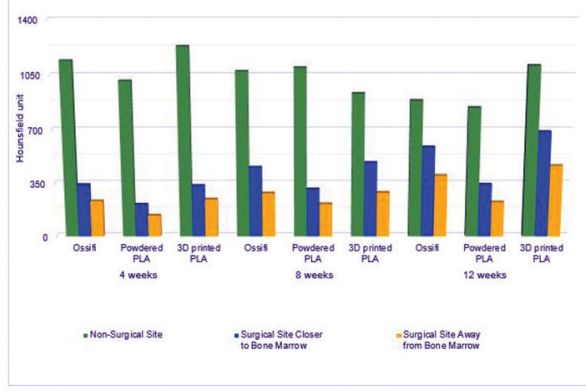

Graph 1 Mean radiodensity at surgical site and at nonsurgical site at different time intervals for different materials. 
Table 1 Multiple comparison between surgical site (closer and away from bone marrow)-Tukey's honestly significant difference test

\begin{tabular}{|l|l|l|l|l|}
\hline $\begin{array}{l}\text { Dependent } \\
\text { variable (weeks) }\end{array}$ & $\begin{array}{l}\text { Multiple comparison using Tukey's } \\
\text { HSD test }\end{array}$ & $p$ for Ossifi & $p$ for powdered PLA & $p$ for 3D printed PLA \\
\hline 4 & $\begin{array}{l}\text { Surgical site closer to bone marrow- } \\
\text { surgical site away from bone marrow }\end{array}$ & 0.304 & 0.889 & 0.838 \\
\hline 8 & $\begin{array}{l}\text { Surgical site closer to bone marrow- } \\
\text { surgical site away from bone marrow }\end{array}$ & 0.003 & 0.750 & 0.237 \\
\hline 12 & $\begin{array}{l}\text { Surgical site closer to bone marrow- } \\
\text { surgical site away from bone marrow }\end{array}$ & 0.520 & 0.244 & 0.327 \\
\hline
\end{tabular}

Abbreviations: 3D, three-dimensionally; HSD, honestly significant difference; PLA, polylactic acid.

Table 2 Multiple comparison at 4, 8, and 12 weeks using Tukey's honestly significant difference test

\begin{tabular}{|l|l|l|l|l|}
\hline Dependent variable (weeks) & Group & Mean difference & SE & $p$ \\
\hline \multirow{4}{*}{4} & Ossifi-PLA powdered & 130.5 & 11.43 & $0.003^{*}$ \\
\cline { 2 - 5 } & PLA powdered-3D-printed PLA & -124.5 & 11.43 & $0.003^{*}$ \\
\cline { 2 - 5 } & 3D-printed PLA-Ossifi & -31.0 & 68.1 & 0.866 \\
\hline \multirow{5}{*}{12} & Ossifi-PLA powdered & 143.50 & 68.19 & 0.236 \\
\cline { 2 - 5 } & PLA powdered-3D-printed PLA & 174.5 & 68.19 & 0.160 \\
\cline { 2 - 5 } & 3D-printed PLA-Ossifi & 31.0 & 68.1 & 0.896 \\
\hline & Ossifi-PLA powdered & 245.0 & 83.09 & 0.117 \\
\cline { 2 - 5 } & PLA powdered-3D printed PLA & 344.5 & 83.09 & 0.051 \\
\cline { 2 - 5 } & 3D printed PLA-Ossifi & 99.5 & & 0.531 \\
\hline
\end{tabular}

Abbreviations: 3D, three dimensionally; PLA, polylactic acid; SE, standard error.

${ }^{*} p$-Statistically significant.

Table 3 Kruskal-Wallis test for the comparison of radio density at different time intervals (4, 8, and 12 weeks) with different materials (groups 1, 2, and 3)

\begin{tabular}{|l|l|l|l|}
\hline Time interval & Group & $\begin{array}{l}\text { Mean rank (surgical site closer to } \\
\text { bone marrow) }\end{array}$ & $\begin{array}{l}\text { Mean rank (surgical site away } \\
\text { from bone marrow) }\end{array}$ \\
\hline \multirow{4}{*}{ 4weeks } & Group1-Ossifie & 4.5 & 4.25 \\
\cline { 2 - 4 } & Group2-PLA (POWDERED) & 1.5 & 1.5 \\
\cline { 2 - 4 } & Group3-3D printed PLA & 4.5 & 4.75 \\
\cline { 2 - 4 } & Total & $n=6$ & $n=6$ \\
\hline \multirow{5}{*}{8 weeks } & Group1-Ossifie & 3.5 & 4.0 \\
\cline { 2 - 4 } & Group2-PLA (POWDERED) & 1.5 & 2.5 \\
\cline { 2 - 4 } & Group3-3D printed PLA & 5.5 & 4.0 \\
\cline { 2 - 4 } & Total & $n=6$ & $n=6$ \\
\hline \multirow{3}{*}{ weeks } & Group1-Ossifie & 3.5 & 4.0 \\
\cline { 2 - 4 } & Group2-PLA (POWDERED) & 1.5 & 1.5 \\
\cline { 2 - 4 } & Group3-3D printed PLA & 5.5 & $n .0$ \\
\cline { 2 - 4 } & Total & $n=6$ & $n$ \\
\hline
\end{tabular}

the histological sections revealed a higher scoring sequence of incomplete bone formation as compared to complete bone formation pattern. In groups 1 and 2, the histological sections revealed no scaffolds, whereas in group 3, the partial presence of scaffold was observed.

\section{Discussion}

The autogenous bone is considered as gold standard for massive reconstructive procedures, but they do lack the size, shape, geometric requirements of the defect site and the morbidity of the harvesting site. Bone tissue engineering has given biocompatible materials that can be used as scaffolds or for manipulating the functions of bone-forming cells or guiding the new bone into the desired shape. ${ }^{10,14}$ Polyglycolide and copolymers are the most commonly used biodegradable polymers in tissue engineering. ${ }^{15}$ The forms of PLA, PLGA, and copolymers are used in various forms such as tubes, screws, plates, resorbable suture materials, for guided bone regeneration/guided tissue regeneration, membranes, 
or barriers. ${ }^{12,16-18}$ Hence, in this study, the powdered form of PLA and 3D-printed PLA have been tested in an animal model to understand their efficiency in the direction of bone formation and scaffold degradation. The 3D-printed PLA has the merit of ease of designing and ease of reproducing the required geometry when compared to the powdered or particulate forms (which may not be as precise as 3D-printed material in conforming to the shape of the defects)..$^{19}$ Earlier research conducted by Zhang et al in 2012 has also reported advantages of 3D scaffold designing over the other material. ${ }^{20}$ The current study shows that at the end of 12 weeks, the radiodensity of the surgical sites is around 400-600 $\mathrm{HU}$ and that of nonsurgical sites is around 800-1200 HU. There was definitive bone formation in all three groups, but the maturity level of the bone was lacking at all surgical sites in comparison to the nonsurgical sites. The radiodensity in all three groups of the present study indicates an immediate bone response and formation closer to the bone marrow rather than away from it. ${ }^{12}$ The histological finding at the fourth week in this study showed that in both groups 2 and 3 the PLA materials elicited shallow bone formation in comparison to the particulate graft. The defect size had reduced and a partial scaffold material was present. This indicates that 3D-printed PLA material was not rejected by the healthy living bone; a positive apposition of new bone surrounding the PLA material was also observed. The 3D-printed PLA being designed at $40 \mu$ in the current study showed early signs of bone regeneration. With an increase in porosity, a subsequent increase in scaffold degradation and bone formation is appreciated in 3D-printed materials. ${ }^{21,22}$

The present study on 3D-printed PLA was tested in a continuous defect in an animal model. Future studies should be evaluated with the associated systemic risk factors in vital organs and adjacent connective tissues of the animals. The efficiency of PLA material as an Osseo inductive material can be tested along with other bone forming materials such as hydroxylapatite crystals, $\beta$-tricalcium phosphate, surface-modified PLA materials, and porous PLA materials. They can be researched for the material's success and synergistic effect as well.

\section{Conclusion}

Based on the results of this study, 3D-printed PLA scaffolds showed positive signs of bone regeneration around the material in continuity defects. The radiographic and histological changes of 3D-printed PLA in comparison with other two materials (Ossifi and powdered PLA) seem to have a significant difference, and the 3D-printed PLA material can be a promising alternative bone regenerative material.

\section{Financial Support and Sponsorship}

None.

\section{Conflicts of Interest}

None.

\section{References}

1 Chen YJ, Pao JL, Chen CS, et al. Evaluation of new biphasic calcium phosphate bone substitute: Rabbit femur defect model and preliminary clinical results. J Med Biol Eng 2017;37(1):85-93

2 Elsalanty ME, Genecov DG. Bone grafts in craniofacial surgery. Craniomaxillofac Trauma Reconstr 2009;2(3):125-134

3 Roberts TT, Rosenbaum AJ. Bone grafts, bone substitutes and orthobiologics: the bridge between basic science and clinical advancements in fracture healing. Organogenesis 2012;8(4):114-124

4 Sumer M, Keles GC, Cetinkaya BO, Balli U, Pamuk F, Uckan S. Autogenous cortical bone and bioactive glass grafting for treatment of intraosseous periodontal defects. Eur J Dent 2013;7(1):6-14

5 Ono Y, Dávalos Herrera DA, Woodmass JM, Boorman RS, Thornton GM, Lo IK. Graft augmentation versus bridging for large to massive rotator cuff tears: a systematic review. Arthroscopy 2017;33(3):673-680

6 Fernández RF, Bucchi C, Navarro P, Beltrán V, Borie E. Bone grafts utilized in dentistry: an analysis of patients' preferences. BMC Med Ethics 2015;16(1):71

7 Dimitriou R, Jones E, McGonagle D, Giannoudis PV. Bone regeneration: current concepts and future directions. BMC Med 2011;9:66

8 Subramaniam P, Kumar K, Ramakrishna T, Bhadranna A. Bone regeneration with plasma-rich-protein following enucleation of traumatic bone cyst. Eur J Dent 2013;7(3):377-381

9 Aghaloo TL, Hadaya D. Basic principles of bioengineering and regeneration. Oral Maxillofac Surg Clin North Am 2017;29(1):1-7

10 Pang L, Hao W, Jiang M, Huang J, Yan Y, Hu Y. Bony defect repair in rabbit using hybrid rapid prototyping polylacticco-glycolic acid/ $\beta$-tricalciumphosphate collagen I/apatite scaffold and bone marrow mesenchymal stem cells. Indian J Orthop 2013;47(4):388-394

11 Saba N, Jawaid M, Al-Othman O. An overview on polylactic acid, its cellulosic composites and applications. Current Organic Synthesis. 2017;14(2):156-70.

12 da Silva Pereira SL, Sallum AW, Casati MZ, et al. Comparison of bioabsorbable and non-resorbable membranes in the treatment of dehiscence-type defects. A histomorphometric study in dogs. J Periodontol 2000;71(8):1306-1314

13 Nishimoto H, Kokubu T, Inui A, et al. Ligament regeneration using an absorbable stent-shaped poly-L-lactic acid scaffold in a rabbit model. Int Orthop 2012;36(11):2379-2386

14 James R, Laurencin CT. Regenerative engineering and advanced materials science. MRS Bulletin. 2017;42(8):600-607.

15 Ge Z, Tian X, Heng BC, Fan V, Yeo JF, Cao T. Histological evaluation of osteogenesis of 3D-printed poly-lactic-co-glycolic acid (PLGA) scaffolds in a rabbit model. Biomed Mater 2009; 4(2):021001

16 Anseth KS, Metters AT, Bryant SJ, Martens PJ, Elisseeff JH, Bowman $\mathrm{CN}$. In situ forming degradable networks and their application in tissue engineering and drug delivery. J Control Release 2002;78(1-3):199-209 
17 Akagi $\mathrm{H}$, Ochi $\mathrm{H}$, Soeta $\mathrm{S}$, et al. A comparison of the process of remodeling of hydroxyapatite/poly-D/L-lactide and betatricalcium phosphate in a loading site. BioMed Res Int 2015;2015:730105

$18 \mathrm{Xu}$ X, He L, Zhu B, Li J, Li J. Advances in polymeric materials for dental applications. Polymer Chemistry. 2017;8(5):807-823

19 Tajbakhsh S, Hajiali F. A comprehensive study on the fabrication and properties of biocomposites of poly(lactic acid)/ceramics for bone tissue engineering. Mater Sci Eng C 2017;70(Pt 1): 897-912

20 Zhang X, Qi YY, Zhao TF, et al. Reconstruction of segmental bone defects in the rabbit ulna using periosteum encapsulated mesenchymal stem cells-loaded poly (lactic-co-glycolic acid) scaffolds. Chin Med J (Engl) 2012;125(22):4031-4036

21 Zhang H, Mao X, Du Z, et al. Three dimensional printed macroporous polylactic acid/hydroxyapatite composite scaffolds for promoting bone formation in a critical-size rat calvarial defect model. Sci Technol Adv Mater 2016;17(1):136-148

22 Danoux CB, Barbieri D, Yuan H, de Bruijn JD, van Blitterswijk CA, Habibovic P. In vitro and in vivo bioactivity assessment of a polylactic acid/hydroxyapatite composite for bone regeneration. Biomatter 2014;4:e27664 